\title{
Strength Requirements for Shear Diaphragms Used for Stability Bracing of Steel Beams
}

\author{
O. Ozgur Egilmez ${ }^{1}$; Mustafa Vardaroglu²; and Andac Akbaba ${ }^{3}$
}

\begin{abstract}
Light-gauge metal sheeting is often used in steel building and bridge industries as concrete deck formwork. Besides providing support to the fresh concrete, the sheeting acts as a shear diaphragm and provides continuous lateral bracing to the top flanges of the beams to which they are attached. An adequate stability-bracing system must possess sufficient stiffness and strength to control deformations and brace forces. Strength requirements for shear diaphragms are currently not well established. A computational study was conducted to develop strength requirements for shear diaphragms bracing simply supported steel beams. Both end-fastener and sidelap-fastener connections were modeled in the study. To the best of the authors' knowledge, this is the first study to quantify the stability-induced forces in sidelap fasteners. The effects of deck width and number of end and sidelap fasteners on brace forces were investigated. Expressions were developed to estimate the stability-induced brace forces in end-fastener and sidelap-fastener connections. DOI: 10.1061/(ASCE)ST.1943-541X.0001706. @ 2016 American Society of Civil Engineers.
\end{abstract}

Author keywords: Shear diaphragms; Steel beams; Bracing; Strength requirements; Construction.

\section{Introduction}

Light-gauge metal sheeting is often used in the construction industry as composite floor decking, roof decking, or siding. In the steelbuilding and bridge industries, in addition to providing support to the concrete deck during construction, metal deck sheeting also contributes to the structural stability of the beams or girders to which they are attached. Deck sheets act as a shear diaphragm and provide continuous lateral bracing to the top flange of noncomposite beams and girders by restraining the warping deformations along the length of the beams. In the building industry, deck sheets are typically continuous over the tops of the beams and are fastened directly to the beam flanges. In design for construction, these beams are generally considered to be continuously braced against lateral torsional buckling for positive bending. In the bridge industry, current AASHTO load and resistance factor design (LRFD) specifications (2014) do not allow the use of bridge deck sheets as a bracing source for steel bridge I-girders due to the eccentric connection detail. Conventional steel-bridge bracing systems consist of intermediate cross frames or diaphragms that reduce the unbraced length of the girders, thus increasing the buckling capacity during construction. Recent studies have demonstrated that metal deck sheets can also significantly increase the buckling capacity of bridge girders by providing a relatively simple modification to the eccentric connection detail (Egilmez et al. 2007, 2012). Using metal deck sheets as a bracing source during construction can lead to significant decreases in the number of

\footnotetext{
${ }^{1}$ Associate Professor, Dept. of Civil Engineering, Izmir Univ. of Economics, Izmir 35330, Turkey (corresponding author). E-mail: ozgur. egilmez@ieu.edu.tr

${ }^{2} \mathrm{Ph} . \mathrm{D}$. Candidate, Dept. of Civil Engineering, Izmir Institute of Technology, Izmir 35430, Turkey.

${ }^{3}$ M.Sc. Candidate, Dept. of Civil Engineering, Izmir Institute of Technology, Izmir 35430, Turkey.

Note. This manuscript was submitted on February 11, 2016; approved on September 22, 2016; published online on November 18, 2016. Discussion period open until April 18, 2017; separate discussions must be submitted for individual papers. This paper is part of the Journal of Structural Engineering, (C) ASCE, ISSN 0733-9445.
}

intermediate cross frames or diaphragms that need to be utilized. The recommendations from these studies were implemented on two simply supported steel I-girder bridges in Houston, Texas (Egilmez et al. 2016). Utilizing metal deck forms for bracing allowed the bridges to be designed with no intermediate cross frames. This enabled the elimination of a total of 680 intermediate diaphragms that would have been required in a bridge with conventional bracing. However, due to the lack of a comprehensive design procedure for diaphragm bracing, full-scale laboratory tests were conducted to ensure bridge safety during construction.

The general philosophy for the design of stability-bracing systems is to enable the braced member to support the design loads while controlling deformations. In order to achieve this, a bracing system must have sufficient stiffness and strength (Winter 1960). Shear diaphragms possess a substantial amount of stiffness and strength in the plane of the diaphragm. However, the strength requirements for shear diaphragms are not well established. The most-significant works that address strength requirements for shear diaphragms were conducted by Helwig and Yura (2008a, b), who performed a finite element-based study of I-shaped stocky beams with web slenderness ratio $\left(h / t_{w}\right)$ equal to 60 . Strength requirements were proposed for shear diaphragms used to brace such beams. However, these proposed requirements were based solely on the end fasteners that connect shear diaphragms to structural elements at the ends of the diaphragms. The effects of sidelap fasteners on brace forces were ignored, which resulted in significantly conservative estimates of end-fastener brace forces.

A parametrical study was conducted to develop strength requirements for shear diaphragms used to brace both stocky and slender simply supported steel I-beams, in the purpose of achieving morerealistic estimates of both end-fastener and sidelap-fastener brace forces. Past studies (Davies and Bryan 1982; Luttrell 1981) on shear diaphragm strength and stiffness showed that the shear strength is generally controlled by three factors: shear strength of the longitudinal end connections, shear strength at interior connections between panels, and local or global buckling of the diaphragm. Therefore, strength requirements for shear diaphragms should address both end-fastener and sidelap-fastener connections. This was achieved by utilizing a simple finite-element analytical 


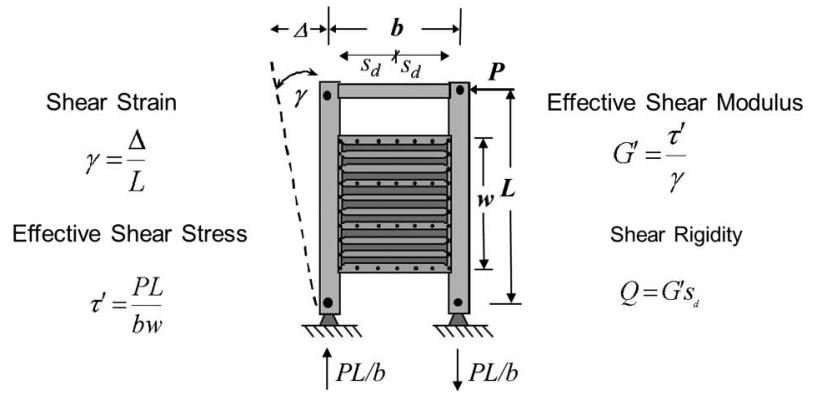

Fig. 1. Cantilever shear test frame

(FEA) model, originally developed by Davies and Bryan (1982) to investigate fastener forces resulting from lateral loading applied to building frames. End and sidelap fasteners were modeled separately to enable the direct calculation of fastener forces. To the best of the authors' knowledge, this is the first study to quantify stability-induced forces in sidelap fasteners.

Background information is presented, followed by a description of the finite-element model, its verification, and an overview of the study. Then, after an examination of the strength behavior of shear diaphragms, the strength requirements for end-fastener and sidelap-fastener connections of shear diaphragms used to brace steel beams are discussed, followed by a brief conclusion.

\section{Background Information}

The property of shear diaphragms that is of interest for bracing purposes is the shear rigidity, which is often denoted by the variable $Q$, which has units of force per unit radian $[\mathrm{kN} / \mathrm{rad}$ (kip/rad)]. Shear rigidity, $Q$, is calculated as the product of the effective shear modulus, $G^{\prime}$, and the tributary width of a diaphragm bracing a single beam, $s_{d}$. The effective shear modulus can be determined experimentally utilizing a testing frame similar to the one shown in Fig. 1. The traditional definition of $G^{\prime}$ would be the shear stress divided by the shear strain. However, since the shear stress versus strain relationship of the corrugated sheeting is generally not a linear function of the material thickness (Luttrell 1981), an effective shear stress is utilized.

There have been a number of research investigations on the bracing behavior of shear diaphragms. Helwig and Frank (1999) presented finite-element results that demonstrated the effects of moment gradient and load height on the bracing behavior of shear diaphragms used to brace slender beams with $h / t_{w}$ greater than 60. They recommended the following expression to approximate the buckling capacity of steel beams braced by shear diaphragms:

$$
M_{c r}=C_{b}^{*} M_{g}+m Q d
$$

where $M_{c r}=$ buckling capacity of the diaphragm braced beam; $M_{g}=$ capacity of the beam with no bracing; $Q=$ shear rigidity of the deck; $C_{b}^{*}=$ moment gradient factor that considers load height effects (Ziemian 2010); $d=$ depth of the beam; and $m=$ factor that depends on load position.

The expression given in Eq. (1) is applicable to a perfectly straight girder. Therefore, using such an equation to solve for the deck stiffness for a given moment would be analogous to the ideal stiffness requirement given by

$$
G_{i}^{\prime}=\frac{Q_{i}}{s_{d}}=\frac{\left(M_{u}-C_{b}^{*} M_{g}\right)}{m d s_{d}}
$$

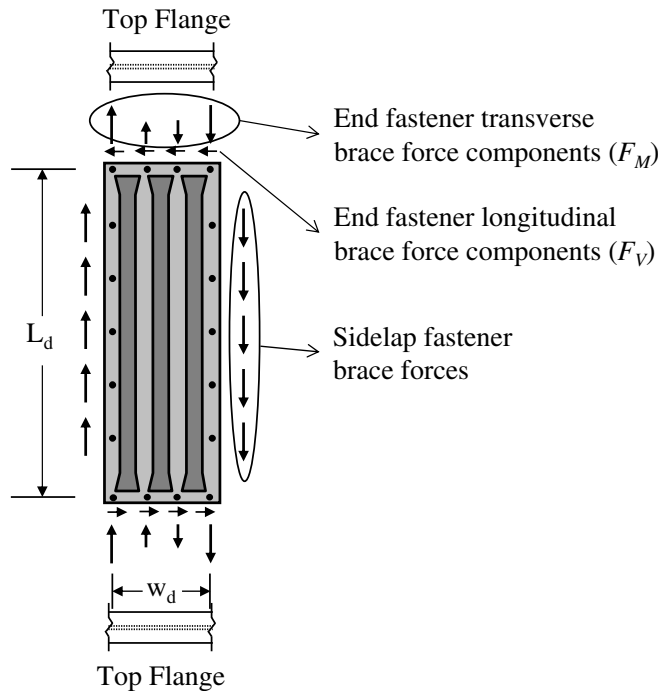

Fig. 2. Free-body diagram of a single deck sheet

where $G_{i}^{\prime}=$ effective ideal shear stiffness of diaphragm; $Q_{i}=$ ideal shear rigidity of diaphragm; $M_{u}=$ design moment along the beam; and other parameters have been defined in Eq. (1). The brace stiffness required for a structural member to reach a specific load level or buckling capacity is often called the ideal stiffness. Helwig and Yura $(2008 \mathrm{a}, \mathrm{b})$ conducted large-displacement analysis on shear diaphragm braced beams with $h / t_{w}=60$ in order to develop stiffness and strength requirements for shear diaphragms used for stability bracing of steel beams. In their study, the ideal stiffness of diaphragms was selected as the diaphragm stiffness from an eigenvalue buckling analysis that produced a beam bending stress of $345 \mathrm{MPa}$. Helwig and Yura (2008b) recommended providing four times the ideal stiffness to effectively control deformations and brace forces $\left(G_{\text {reg } / \mathrm{d}}^{d}=\right.$ required effective diaphragm stiffness $\left.=4 G_{i}^{\prime}\right)$.

Helwig and Yura (2008b) also found that the strength of shear diaphragms is a function of beam length and depth. Provided that the stiffness of a diaphragm is equal to four times the ideal value, Helwig and Yura (2008b) recommended using the following expressions to calculate the transverse $\left(F_{M}\right)$ and longitudinal $\left(F_{V}\right)$ brace force components that develop at end fasteners:

$$
\begin{gathered}
F_{M}=\frac{0.001 M_{u} L}{k d^{2}} \\
F_{V}=2\left(\frac{0.001 M_{u} L w_{d}}{L_{d} n_{e} d^{2}}\right)
\end{gathered}
$$

where $M_{u}=$ design moment that corresponds to a stress level of $345 \mathrm{MPa} ; L=$ spacing between discrete bracing points that prevent twist; $d=$ depth of the section; $L_{d}=$ length of the sheet; $w_{d}=$ width of the sheet; $n_{e}=$ number of end fasteners; and $k=$ factor that depends on number of end fasteners. The assumed orientations of the transverse $\left(F_{M}\right)$ and longitudinal $\left(F_{V}\right)$ end-fastener brace forces are depicted in Fig. 2. The free-body diagram (FBD) shown in Fig. 2 belongs to a single deck sheet with four end and five sidelap fasteners and also includes the brace forces that develop at the sidelap fasteners. However, sidelap-fastener brace forces were ignored in Helwig and Yura's (2008a, b) study. The resultant total end-fastener brace force can be calculated by taking the square root of the summation of the squares of the preceding expressions. 


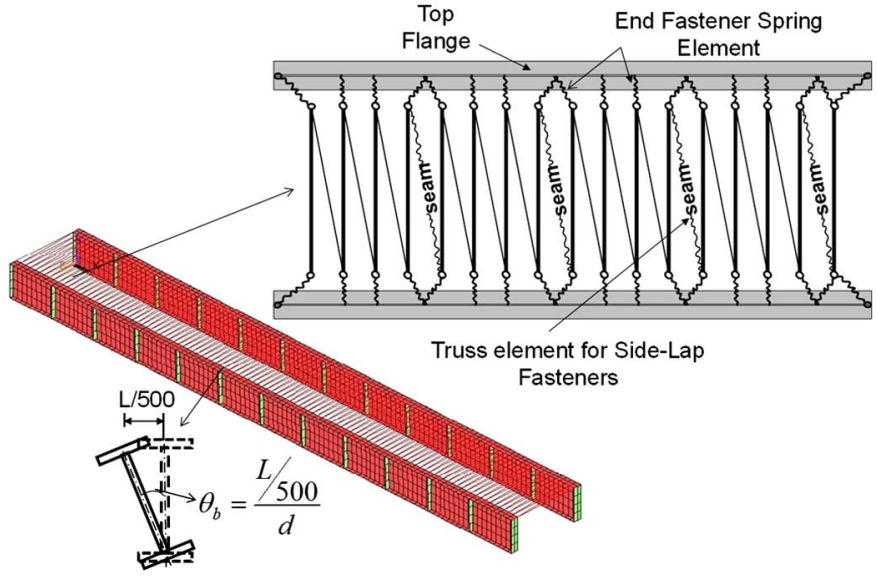

Fig. 3. FEA model

\section{FEA Model}

\section{FEA Model of Beams}

The three-dimensional (3D) finite-element program ANSYS was used to perform parametric studies on the behavior of steel I-beams braced by shear diaphragms. The FEA model consisted of a simply supported twin-beam system with a shear diaphragm connected to the top flanges, as depicted in Fig. 3. The shear diaphragm provided the only bracing against lateral torsional buckling. All elements used in the FEA model possessed linear-elastic material properties. The beams and web stiffeners were meshed with eight-node shell elements. Two elements were used to model the flanges, and four to six elements for the webs, depending on the depth of the sections. The aspect ratio of the elements ranged between 1.2 and 2.9. The beams were simply supported with lateral movement prevented at the top and bottom flanges at the supports. Nonlinear effects were not considered since the purpose of the study was to develop strength requirements for shear diaphragms in the construction phase, when the stresses in the beams are well below the yield strength.

Initial imperfections play an important role in the magnitude of brace forces that develop in bracing members. Wang and Helwig (2005) showed that brace forces are directly proportional to the magnitude of initial imperfections for beams braced by cross frames or diaphragms. Wang and Helwig (2005) also showed that the worst-case imperfection for maximizing brace forces consists of a lateral sweep of the compression flange, while the other flange remains essentially straight. For the magnitude of lateral sweep of the top flange, both Wang and Helwig (2005) and Helwig and Yura (2008a, b) suggest doubling the $L_{b} / 1,000$ limit, where $L_{b}$ is the unbraced length of the beam, set by the AISC Code of standard practice (2010) on the variation in straightness between points of lateral supports in building applications. This is considered necessary due to possible additional out-of-plumpness and uneven bearing supports in bridge constructions, which may result in larger imperfections. In the current study, the shape and magnitude recommended by Wang and Helwig (2005) for initial imperfections were adopted, as illustrated in Fig. 3.

\section{FEA Model of Shear Diaphragm}

Steel deck forms are generally modeled as shear diaphragms that restrain the lateral movement of top flanges of steel beams to which they are attached. Deck forms commonly used in the construction industry consist of steel deck sheets with a cover length of 610 and 914 mm (CANAM 2006; Luttrell 1981). These forms are manufactured with different number of ribs. The 610-mm-wide steel decks are available in two, three, or four ribs, and those with a cover length of $914 \mathrm{~mm}$ are available in either three or six ribs. Since end fasteners are placed in rib valleys, the number of ribs in a deck form plays an important role in the arrangement of end fasteners. End fasteners can be placed in the valley of each rib, creating a fully fastened deck system; or in alternate valleys, creating a partially fastened deck system. Strength requirements for shear diaphragms were initially developed by utilizing a model of the fully fastened 610-mm (24-in.)-wide deck form sheet with three ribs, four end fasteners, five sidelap fasteners, and deck thickness of $1.52 \mathrm{~mm}$ [16 gauge (ga)]. However, the FEA model of the deck form sheet used in this study facilitated changes in the width of the deck and number of end and sidelap fasteners. Additional analyses were then conducted with different deck widths and numbers of end and sidelap fasteners to investigate the effects of these parameters on the strength of end-fastener and sidelap-fastener connections.

The FEA model used in this study for shear diaphragms was originally developed by Davies and Bryan (1982) to investigate fastener forces resulting from lateral loading applied to building frames. In their study, Davies and Bryan (1982) simulated the shear stiffness of diaphragms using a series of bars forming a truss, as illustrated in Fig. 3. Each of these small trusses consists of four transverse and three diagonal truss elements and represents a single deck sheet profile. The deck sheet profile initially modeled in this study is a typical deck sheet with three ribs. The transverse truss elements were located at every trough and spanned the centerline of beam top flanges. This type of a representation of deck sheets enabled each end-fastener connection between deck and structural member to be modeled by dimensionless spring elements and be placed at the ends of each transverse truss element. The transverse truss elements were connected to the beam top flange midnodes through dimensionless spring elements. The number of transverse truss elements could be adjusted depending on the number of fasteners used to connect the deck sheet to structural member. These truss elements were 3D uniaxial tensioncompression elements. The stiffness of the transverse elements was taken as being sufficiently high to allow their axial strain to be neglected. The shear stiffness of the deck sheets depended only on the properties of the diagonal elements. The required area of the diagonal truss elements that correspond to a certain shear rigidity was determined using an FEA model of the shear test frame, shown in Fig. 1.

\section{FEA Model of Fasteners}

In both building and bridge forming systems, deck sheets are generally fastened to supporting members along the ends and to each other at sidelaps by mechanical fasteners. Conventional mechanical fasteners for deck sheets are generally 19-mm (3/4-in.)-long tek screws with a $6.3 \mathrm{~mm}(1 / 4 \mathrm{in}$.) diameter. Deck sheet to structural member end fastener connections along the beam length were modeled by dimensionless spring elements possessing equal stiffness in two orthogonal directions, but no rotational stiffness. These spring elements were positioned at the centerline of beam top flanges and connected to the midnode of beam top flanges and the ends of the transverse truss elements. Although the dimensionless spring elements are shown to have finite length in Fig. 3, this representation is merely for illustration purposes. At sidelap locations along the beam length, separate spring elements were used to connect each transverse truss end to the same midnode of beam top flange, as illustrated in Fig. 3. Expressions given by Luttrell (1981) were used 
to quantify the transverse and lateral stiffness of these dimensionless spring elements.

In the representation of shear diaphragm bracing systems, deck sheets adjacent to the supports were assumed to be fastened to structural members (beam, diaphragm, etc.) that span transversely between the supports. The stiffness of these fastener connections was also incorporated in the model by providing additional deck to structural member spring elements that connect the corner nodes of the deck trusses adjacent to the supports to beam midnodes at the supports.

Sidelap-fastener connections were modeled by a transverse truss element that connects opposite ends of adjacent small trusses as shown in Fig. 3. The stiffness of sidelap transverse truss elements represented the combined stiffness of all those sidelap-fastener connections along the seam. Texas Department of Transportation (TxDOT) permanent metal deck form (PMDF) standards (TxDOT 2015) require a maximum center-to-center spacing of $450 \mathrm{~mm}$ (18 in.) at sidelaps. The number of fasteners at sidelap locations considered in this study ranged from two to six. Two and six fasteners correspond to deck lengths of approximately 1,300 and 2,750 $\mathrm{mm}$ (50 and $110 \mathrm{in}$.), respectively. These deck lengths are in the lower and upper limits of common deck lengths utilized in the building and bridge industries. Expressions given by Luttrell (1981) were used to quantify the stiffness of one sidelap-fastener connection. All elements used in the FEA model of the deck bracing system also possessed linear-elastic material properties. Since bracing systems are generally designed to remain in the elastic range to control deformations, nonlinear behavior of the deck system was not considered essential to the study.

\section{Verification of the FEA Model}

The accuracy of the FEA simulation was verified by comparing the buckling behavior of a $15-\mathrm{m}$ (50-ft) twin-girder system braced by metal deck sheets with that of the FEA simulation. The test used in the verification study was a full-scale twin-girder buckling test conducted at the structural engineering laboratory of University of Houston (Egilmez et al. 2012). The girders were U.S. wide-flange beams, W760 × 134 (U.S. W30 ×90), with a depth of $750 \mathrm{~mm}$ (29.5 in.). Point loads were applied to the girders through two gravity load simulators at third points. The deck form system utilized in the test setup represented a forming system used in the bridge industry with a modified connection detail. The modified connection detail consisted of transverse stiffening angles that spanned between the top flanges of the girders. Detailed information on the modified connection detail is given in Egilmez et al. (2007, 2012). The deck forms used in the test were 610-mm (24-in.)-wide preclosed bridge metal deck forms with three ribs, fastened to the beam top flanges at the ends by four end fasteners. The deck forms were $2,750 \mathrm{~mm}$ (108 in.) long with five sidelap fasteners at sidelaps, and were $1.22 \mathrm{~mm}$ (18 ga) thick. The effective shear stiffness of the deck form system in the test was measured as 7,184 kN/m-rad (41 kips/in.); which corresponded to a deck shear rigidity of 9,842 kN/rad (2,212 kips/rad) (Egilmez et al. 2007). A full description of the test set-up is given in Egilmez et al. (2012).

Fig. 4 shows the midspan moment versus midspan total twist/ initial twist behavior of the W760 $\times 134$ (U.S. W30 $\times 90$ ) girders braced by a shear diaphragm, and that of the truss panel FEA simulation. An FEA model of a cantilever shear test frame was used to calibrate the area of the diagonal truss elements of the shear diaphragm truss panel FEA model. The areas of the diagonal truss elements were adjusted so that the shear stiffness of the model matched that of the deck form system used in the test. The calibrated diaphragm model was then integrated into the twin-beam

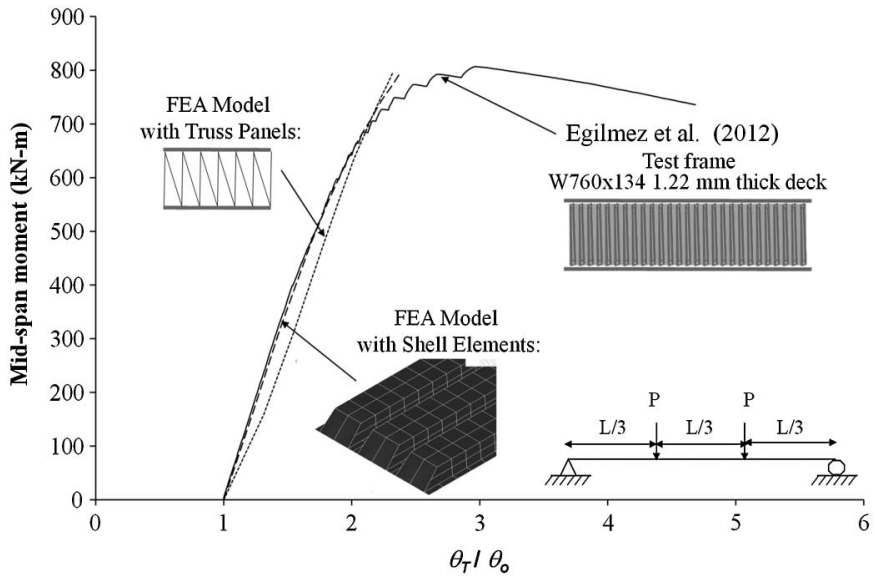

Fig. 4. Midspan moment-twist behavior of test and FEA simulations

FEA model. Fig. 4 also depicts the midspan moment versus total twist/initial twist behavior of a more detailed FEA model of the twin-beam and shear diaphragm system employed by Egilmez et al. (2005). In their study, Egilmez et al. (2005) used shell elements to model the entire corrugation of the metal deck system and dimensionless spring elements to model the end-fastener and sidelapfastener connections. The shell element FEA model had excellent agreement with the twist behavior of the test beam and shear diaphragm bracing system, whereas the twist values predicted by the truss panel model were approximately $4.7 \%$ higher. However, the truss panel model was substantially more computationally efficient. Due to the higher twist values of the truss panel model, brace forces predicted by this model would be more conservative than those predicted by the shell element FEA model. Since elastic materials were used in both models, the inelastic behavior of the test specimen was not captured.

\section{Overview of Study}

Six doubly symmetric sections with web slenderness ratios $\left(h / t_{w}\right)$ of 60, 100, and 160 were considered in the study, as shown in Fig. 5. The depths of beams with $h / t_{w}$ of 60 were 366 and $732 \mathrm{~mm} \mathrm{(14.4}$

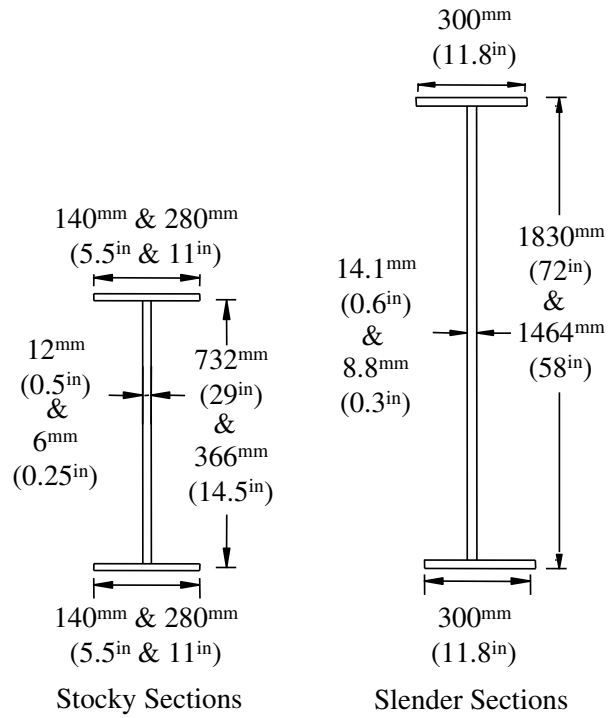

Fig. 5. Cross sections used in the study 
and 28.8 in.) and they will be referred to as Stocky 1 and 2, respectively. The respective flange widths of Stocky 1 and 2 beams were 140 and $280 \mathrm{~mm}$ (5.5 and $11 \mathrm{in}$.). Flange slenderness ratio $\left(b / t_{f}\right)$ of these two stocky beams was 7.8. Doubly symmetric sections with $h / t_{w}$ of 100 and 160 will be referred to as Slender-100 1 and 2 and Slender-160 1 and 2, respectively. The depth of Slender-100 1 and Slender-160 1 beams were 1,464 mm (57.6 in.), whereas the depth of Slender-100 2 and Slender-160 2 beams were 1,830 mm (72 in.). The respective flange width and $b / t_{f}$ ratio of these slender beams were $300 \mathrm{~mm}$ (11.8 in.) and 6. Slender beams had transverse stiffeners with $a / h$ ratio of 1.0 .

For stocky beams, span/depth $(L / d)$ ratios of $15,20,25,30$ and for slender beams, $L / d$ ratios of 10 and 15 were considered. Utilizing cross frames is a common application for increasing the buckling capacity of long-span simply supported bridge I-girders during construction. Sections with longer spans and intermediate cross frames were not investigated in this study; however, work is currently underway to investigate the effects of intermediate cross frames on brace forces. The only loading considered was uniformly distributed loading applied at top flange. Uniformly distributed loading is representative of loading from a poured concrete slab.

As previously discussed, initial analyses were conducted utilizing the FEA model of a specific deck sheet with three ribs and a width of $610 \mathrm{~mm}$ (24 in.). The thickness of the deck sheet was taken as $1.52 \mathrm{~mm}$ (16 ga). The deck sheet was assumed to be fully fastened to the beams at the ends by two fasteners at the corners and two between the ribs. The connections between individual deck sheets were assumed to be provided by five sidelap fasteners at each seam. This specific deck sheet configuration will be referred to as the standard deck sheet configuration in the remainder of the paper. Strength requirements for shear diaphragms were developed for this standard deck sheet configuration. Additional analyses were then conducted to investigate the effects of deck width and number of end and sidelap fasteners on brace forces. Analyses were also conducted with different sheet thicknesses. However, the results indicated that the effect of sheet thickness on brace forces were not significant. Hence, the results presented in this paper are only relevant to deck systems with a sheet thickness of $1.52 \mathrm{~mm}$ (16 ga).

The design moment of the sections investigated in this study was taken as the moment corresponding to an in-plane bending stress equal to $210 \mathrm{MPa}(30 \mathrm{ksi})$ at the outer fiber of the section. This stress level is somewhat arbitrary; however, it represents a greater than expected level of in-plane bending stresses during construction. The property of shear diaphragms relevant to bracing purposes is the shear rigidity, which is denoted by the variable $Q$. For each beam investigated in this study, the ideal shear rigidity $\left(Q_{i}\right)$ was calculated by conducting an eigenvalue buckling analysis on a perfectly straight twin-beam system braced by a shear diaphragm. The area of the diagonal truss elements of the shear diaphragm FEA model was calibrated so that the eigenvalue of the twin-beam system corresponded to the moment level that created a bending stress equal to $210 \mathrm{MPa}(30 \mathrm{ksi})$ at the outer fiber. An FEA model similar to the shear test frame was then used to determine the ideal shear rigidity of the calibrated diaphragm truss model.

For stocky beams, Helwig and Yura (2008b) recommended utilizing four times the ideal stiffness of the diaphragm to control deformations and brace forces. For slender beams, a similar parametrical study was conducted by Vardaroglu (2014). Vardaroglu (2014) also recommended using four times the ideal stiffness to control deformations and brace forces for slender beams with $h / t_{w}$ ratio up to 160 . For each beam analyzed in the study, the area

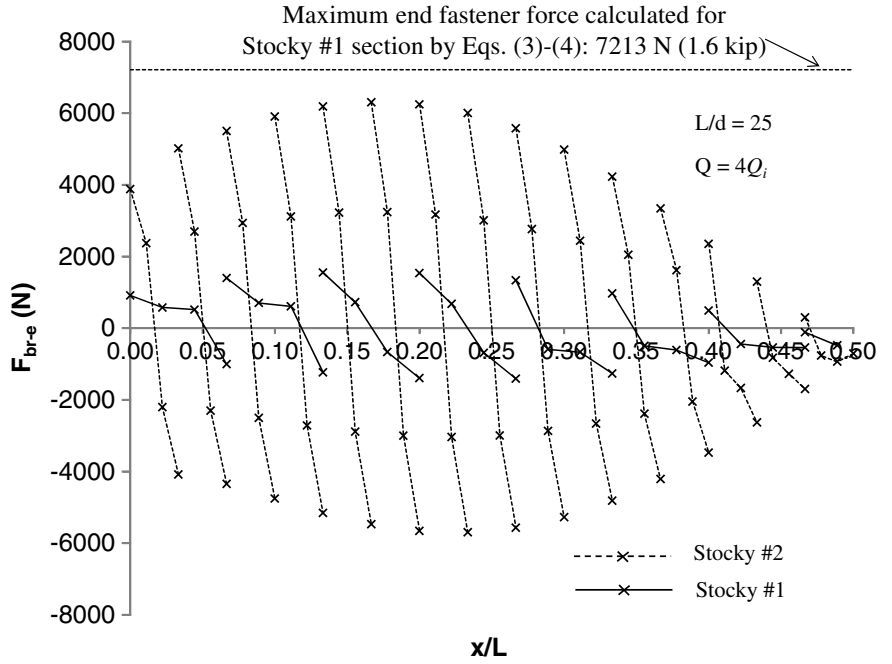

Fig. 6. Distribution of resultant end-fastener brace forces in each deck sheet for stocky beams

of the diagonal truss elements that correspond to diaphragm shear rigidity of four times the ideal value was determined using the shear-frame FEA model. Large displacement analysis, which reflect the effects of geometrical imperfections, was than conducted on the twin-beam FEA model using four times the ideal shear rigidity of the diaphragm to develop strength requirements for shear diaphragms used to brace stocky and slender beams.

\section{FEA Results}

\section{Beams with Stocky Webs}

The standard deck sheet configuration analyzed in this paper, which is shown in Fig. 2, has three ribs, four end fasteners, and five sidelap fasteners. As seen in Fig. 2, both transverse $\left(F_{M}\right)$ and longitudinal $\left(F_{V}\right)$ brace forces develop at end fasteners, whereas only transverse brace forces develop at sidelap fasteners. Fig. 6 depicts the distribution of the resultant end-fastener brace forces along the beam length for Stocky 1 and 2 sections with $L / d$ of 25 and diaphragm rigidity of four times the ideal value. The resultant forces were calculated by taking the square root of the summation of squares of the transverse and longitudinal force components that develop in each end fastener. Due to symmetry, the forces are shown over half the span. Each curve shown in Fig. 6 belongs to a single deck sheet and each marker in a single curve shows the force in one of the four end fasteners in a single sheet.

The horizontal lines at the top and bottom of the vertical axis in Fig. 6 indicate the magnitude of the maximum fastener force, 7,213 N (1.6 kip), calculated by Eqs. (3) and (4) for the Stocky 1 section. This recommended value from literature $[7,213 \mathrm{~N}$ (1.6 kip)] is approximately 4.7 times higher than the maximum resultant fastener force observed in the analysis. Due to scale factors, the corresponding end fastener force for the Stocky 2 section [28,855 N (6.5 kip)] calculated by Eqs. (3) and (4) is not shown in the graph. This recommended value from Eqs. (3) and (4) was 5.1 times higher than the maximum end fastener force obtained from the analysis. These significant differences in end fastener forces are mainly due to the omission of sidelap fastener connections in Helwig and Yura's (2008b) study, and partly due to the effect of differences in design stress levels between the studies (Vardaroglu 2014). The effect of omitting sidelap fasteners on 


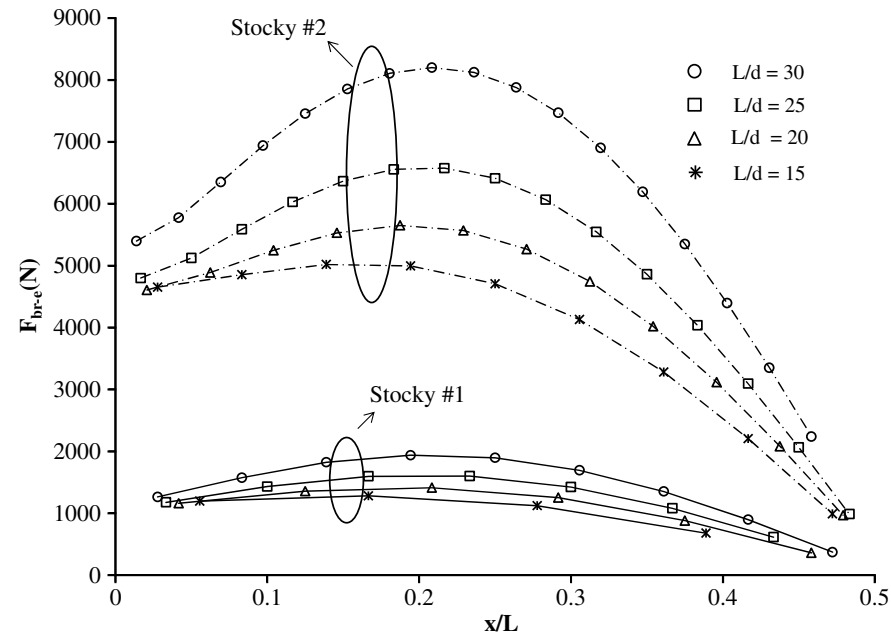

Fig. 7. Distribution of maximum resultant end-fastener brace forces for beams with stocky webs

estimating the magnitude of end fasteners can be observed in Fig. 2. As seen in Fig. 2, the moment produced by the longitudinal $\left(F_{V}\right)$ brace-force couple is balanced by the moments produced by the transverse $\left(F_{M}\right)$ brace-force couples and sidelap brace-force couples. If the sidelap brace-force couples are excluded from the free-body diagram, the contribution of the sidelap brace-force couples to the moment equilibrium has to be provided by an increase in the transverse $\left(F_{M}\right)$ brace-force couples. For this reason, the truss panel FEA model utilized by Helwig and Yura (2008b) resulted in conservative estimates of end-fastener brace forces as predicted earlier.

As depicted in Fig. 6, in a single deck sheet, maximum resultant end-fastener brace forces develop at the edge fasteners, rather than at the intermediate fasteners. The graph in Fig. 7 shows these maximum resultant end-fastener forces in each deck sheet along half the beam length for the two stocky sections for $L / d$ ratios of 15, 20, 25, and 30. Due to symmetry, the forces are shown over half the span. The resultant end-fastener forces were calculated by taking the square root of the squares of $F_{M}$ and $F_{V}$. Each marker on the curves corresponds to the maximum resultant end-fastener brace force $\left(F_{b r-e}\right)$ that develops in a single deck sheet along the length of the beam. These markers are located at the centerline of the deck sheets. Hence, the curves do not initiate from $x / L=0$, but a certain $x / L$ value close to zero depending on the length of the beams. The brace forces for each curve started at a certain value at about $x / L=0$, maximized at a distance of about $x / L=0.20$ from the supports, and approached to zero around midspan. This type of a behavior was observed in all beams analyzed, including the slender beams. The reason for such a behavior is the shear deformations of the top flange that occur along the length of the beams as the uniformly distributed load is applied. The shear deformations maximize at around a normalized distance of $x / L=0.20$. After maximizing at about $x / L=0.2$, the shear deformations of the top flange start to decrease and become almost zero toward the midspan. Around the midspan, lateral displacements dominate the displacement profile of the top flange, which generate no significant brace forces. The curves in Fig. 7 also show that fastener brace forces in the deeper Stocky 2 sections were approximately four times higher than those of the shallower Stocky 1 sections. In addition, fastener forces increased in correspondence with increases in the $L / d$ ratios of the beams for both of the sections. The increase in maximum resultant end-fastener brace forces with

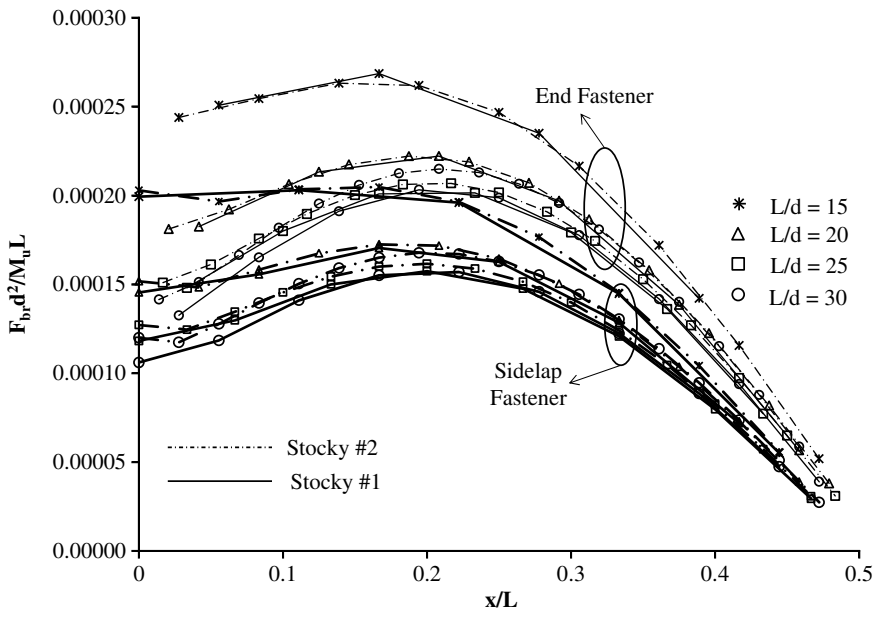

Fig. 8. Distribution of maximum normalized end-fastener and sidelapfastener brace forces for beams with stocky webs

greater beam depth and $L / d$ ratios was consistent with the increase in normalized twist $\left(\theta_{T} / \theta_{o}\right)$ of the beams as the depth and $L / d$ ratios increased (Vardaroglu 2014). Similar behavior was observed for all beams analyzed, both stocky and slender, and for both end-fastener and sidelap-fastener brace forces.

In order to achieve a direct comparison between the maximum resultant end-fastener brace forces of the two stocky sections with different $L / d$ ratios, the maximum resultant end-fastener brace forces presented in Fig. 7 were normalized by the maximum applied beam moment, $M_{u}$, and the ratio of $L / d^{2}$; similar to the normalization procedure followed by Helwig and Yura (2008b). The resultant curves are presented in Fig. 8. Although there were significant differences in magnitudes of the maximum end-fastener brace forces of the two sections, the normalized curves for each $L / d$ ratio shown in Fig. 8 almost coincide. For both sections, the respective maximum normalized end-fastener brace forces were approximately $0.00027,0.00022,0.00021$, and 0.00021 for $L / d$ ratios of $15,20,25$, and 30 . The normalized curves presented in Fig. 8 indicate that maximum normalized brace forces tend to decrease as $L / d$ ratio increases.

An identical normalization procedure was followed for sidelapfastener brace forces, and the resultant curves are also presented in Fig. 8. Similar to the maximum normalized end-fastener brace forces, curves for the maximum normalized sidelap-fastener brace forces also almost coincide for each $L / d$ ratio. For both Stocky 1 and Stocky 2 sections, the respective maximum normalized sidelapfastener forces were approximately $0.00020,0.00017,0.00016$, and 0.00016 for $L / d$ ratios of $15,20,25$, and 30, respectively. Based upon the results presented in Fig. 8, conservative estimates of the maximum normalized end-fastener and sidelap-fastener brace forces for stocky sections can be taken as 0.0003 and 0.00025 , respectively.

\section{Beams with Slender Webs}

The previous section discussed beams with relatively stocky webs, common in building applications. The results presented in the present section focus on deeper sections with $h / t_{w}=100$ and 160 , which are common in plate girders. The slender webs make the beams prone to web shear buckling. However, due to the relatively low stress level [210 MPa (30 ksi)] considered in this study, web shear buckling was not observed in the analyses. $L / d$ ratios of 10 and 15 were considered. For higher $L / d$ ratios, the moment due 


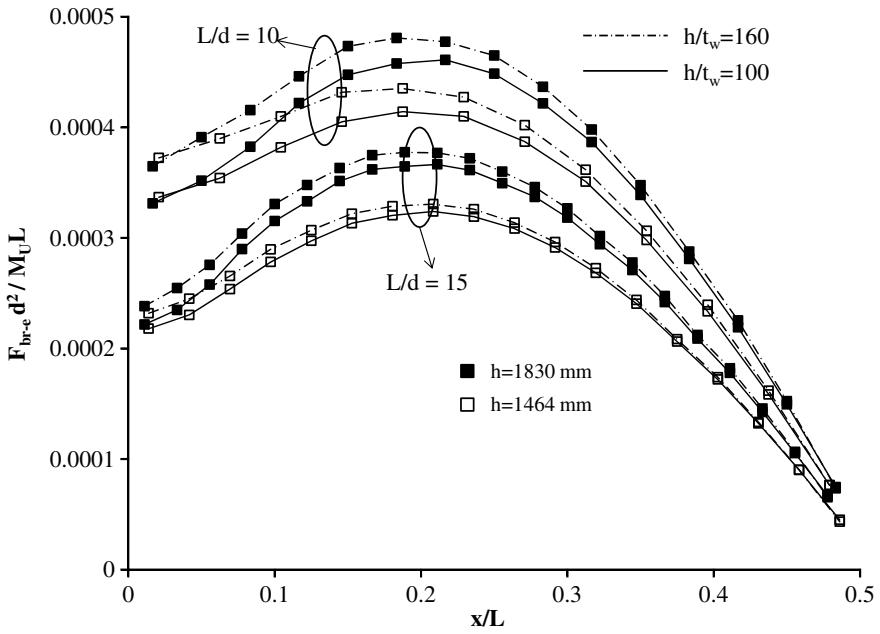

Fig. 9. Distribution of maximum normalized end-fastener brace forces for beams with slender webs

to self-weight of the beams either exceeded or was very close to the buckling capacity of the beams.

Fig. 9 depicts the distribution of the maximum normalized end-fastener brace forces along half the beam length for doubly symmetric slender sections, for diaphragm rigidity of four times the ideal value. The maximum resultant end-fastener brace forces were normalized by the maximum applied beam moment, $M_{u}$, and the ratio of $L / d^{2}$, similar to the normalization procedure followed for stocky sections. The curves for slender sections did not coincide for specific $L / d$ ratios. Rather, the curves were grouped in pairs consisting of sections with the same depth and span to depth ratio but different $h / t_{w}$ ratios. The curves presented in Fig. 9 indicate that maximum normalized brace forces tend to increase as the depth and $h / t_{w}$ ratio of the slender sections increase and $L / d$ ratio decreases. Based upon the results presented in Fig. 9, the normalized maximum end-fastener brace forces can be taken as 0.0005 for slender sections. Although not shown here, similar behavior was observed for normalized sidelap-fastener brace forces. Results indicated that the maximum normalized sidelap-fastener brace forces can be taken as 0.0004 .

\section{Effects of Deck Width and Number of Fasteners on Brace Forces}

The conservative estimates of maximum normalized end-fastener and sidelap-fastener brace-force values recommended earlier were determined for the standard deck sheet configuration. Additional large-displacement analyses were conducted on the sections with different deck widths and number of end and sidelap fasteners to investigate the effects of these parameters on end-fastener and sidelap-fastener brace forces. The maximum normalized endfastener and sidelap-fastener brace force values previously recommended for stocky and slender sections were based on the section that had the highest normalized brace force among all the sections analyzed. For example, Stocky 1 section with $L / d=15$ had the highest maximum normalized end-fastener and sidelap-fastener brace-force values among stocky sections. The slender section with the highest maximum normalized fastener brace-force values was Slender-160 2 section, with $L / d=10, h / t_{w}=160$, and $d=1,830 \mathrm{~mm}$. Due to space limitations, results only from the aforementioned sections are used to demonstrate the effects of deck width and number of end and sidelap fasteners on brace forces. Normalized brace forces developed in other sections were smaller

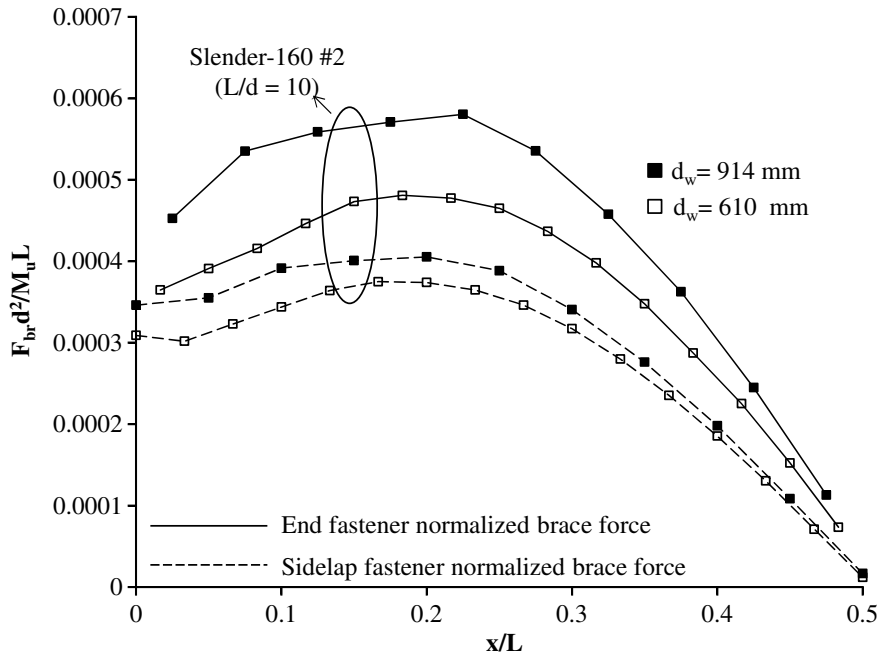

Fig. 10. Effects of deck width on brace forces

than those developed in these sections. Analyses conducted on stocky sections revealed that there was no need to modify the respective recommended values of 0.0003 and 0.00025 for maximum normalized end-fastener and sidelap-fastener brace forces to account for either different deck widths and number of end fasteners. Therefore, for stocky sections, only the effect of number of sidelap fasteners on brace forces is discussed.

A graph of variation in maximum normalized end-fastener and sidelap-fastener brace forces in Slender-160 2 section with respect to deck width is provided in Fig. 10. Results are shown for two different deck widths: 610 and $914 \mathrm{~mm}$ (24 and $36 \mathrm{in}$.). Sheet thickness and number of end and sidelap fasteners were kept the same as in the standard deck configuration. Keeping the number of end fasteners the same while increasing the width of the deck to $914 \mathrm{~mm}$ (36 in.), corresponds to a partially fastened 914-mm (36-in.)-wide deck sheet with six ribs. In such a system, the four end fasteners are placed in alternate rib valleys. The respective maximum normalized end-fastener brace forces were approximately 0.00048 and 0.00058 ; respective maximum normalized sidelap-fastener brace forces were approximately 0.00038 and 0.00040 for deck widths of 610 and $914 \mathrm{~mm}$ (24 and $36 \mathrm{in.}$.). Based upon the results presented in Fig. 10, conservative estimates of maximum normalized end-fastener and sidelap-fastener brace forces for slender sections braced by a shear diaphragm with a deck width of $914 \mathrm{~mm}$ (36 in.) and fastened to top flanges with four end fasteners can be taken as 0.0006 and 0.0004 , respectively.

Fig. 11 shows a graph of the distribution of maximum resultant end-fastener and sidelap-fastener brace forces along half the beam length for Slender-160 2 section for deck systems with three, four, and five end fasteners. Deck width and number of sidelap fasteners were kept the same as in the standard deck sheet configuration. Based upon the results presented in Fig. 10, maximum normalized end-fastener brace forces can be taken as 0.0006 and 0.00045 , and maximum normalized sidelap-fastener brace forces can be taken as 0.0004 and 0.00035 for slender sections with three and five end fasteners, respectively. Similar analyses were conducted on twinbeam and diaphragm systems with two, three, four, five, and six sidelap fasteners for both slender and stocky sections. The results indicated that brace forces increased as number of sidelap fasteners decreased. Based upon the results, conservative estimates of the maximum normalized end-fastener and sidelap-fastener brace forces of slender sections can be taken as $0.0008,0.00065$, $0.00055,0.00050$, and 0.00045 , and $0.00065,0.00055,0.00045$, 


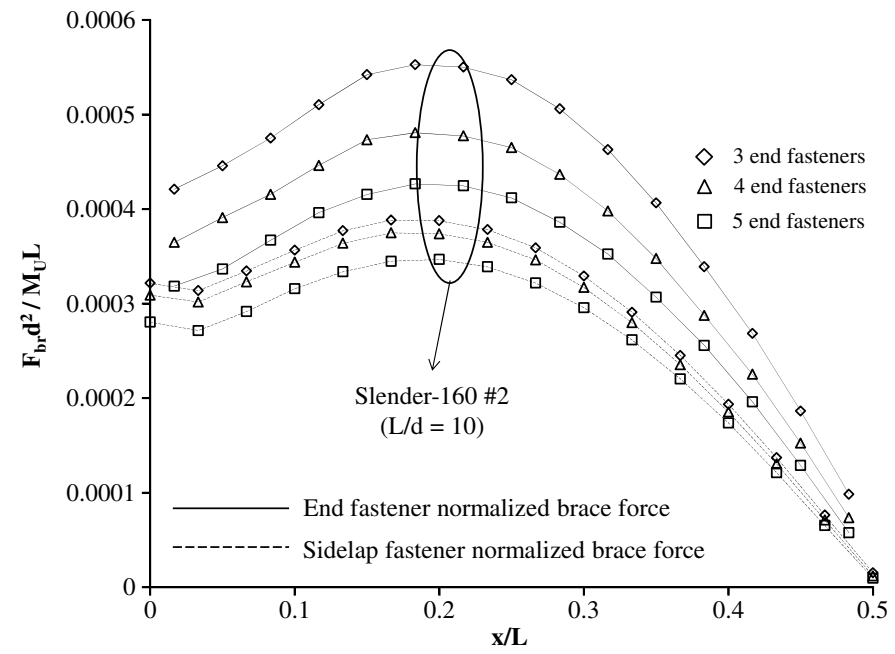

Fig. 11. Effects of number of end fasteners on brace forces

Table 1. Values for $s$ That Reflect the Effects of Number of Sidelap Fasteners on Brace Forces

\begin{tabular}{lccccc}
\hline $\begin{array}{l}\text { Number of } \\
\text { sidelap } \\
\text { fasteners }\end{array}$ & $\begin{array}{c}s_{e} \text { for end-fastener } \\
\text { connections }\end{array}$ & & \multicolumn{2}{c}{$\begin{array}{c}s_{s} \text { for sidelap-fastener } \\
\text { connections }\end{array}$} \\
\cline { 2 - 3 } \cline { 5 - 6 } & $h / t_{w} \leq 60$ & $60<h / t_{w} \leq 160$ & & $h / t_{w} \leq 60$ & $60<h / t_{w} \leq 160$ \\
\hline 2 & 0.00045 & 0.00080 & & 0.00035 & 0.00065 \\
3 & 0.00035 & 0.00065 & & 0.00030 & 0.00055 \\
4 & 0.00030 & 0.00055 & & 0.00025 & 0.00045 \\
5 & 0.00030 & 0.00050 & & 0.00025 & 0.00040 \\
6 & 0.00025 & 0.00045 & & 0.00020 & 0.00035 \\
\hline
\end{tabular}

Table 2. Values for $k$ That Reflect the Effects of Number of End Fasteners on Brace Forces

\begin{tabular}{lccccc}
\hline & \multicolumn{2}{c}{$\begin{array}{c}k_{e} \text { for end-fastener } \\
\text { connections }\end{array}$} & & \multicolumn{2}{c}{$\begin{array}{c}k_{s} \text { for sidelap-fastener } \\
\text { connections }\end{array}$} \\
\cline { 2 - 3 } \cline { 5 - 6 } end fasteners & $h / t_{w} \leq 60$ & $60<h / t_{w} \leq 160$ & & $h / t_{w} \leq 60$ & $60<h / t_{w} \leq 160$ \\
\hline 3 & 1.0 & 1.2 & & 1.0 & 1.0 \\
4 & 1.0 & 1.0 & & 1.0 & 1.0 \\
5 & 1.0 & 0.95 & & 1.0 & 0.9 \\
\hline
\end{tabular}

0.00040 , and 0.00035 for two to six sidelap fasteners, respectively. For stocky sections, reasonable estimates of maximum normalized end-fastener and sidelap-fastener brace forces can be taken as $0.00045,0.00035,0.00030,0.00030$, and 0.00025 , and 0.00035 , $0.00030,0.00025,0.00025$, and 0.00020 for two to six sidelap fasteners, respectively.

\section{Diaphragm Strength Requirements}

Based upon the results presented in the preceding sections, the following expression can be used to obtain reasonable estimates of maximum end-fastener and sidelap-fastener forces:

$$
F_{b r}=C_{r} s k w \frac{M_{u} L}{d^{2}}
$$

where $F_{b r}=$ maximum end-fastener or maximum sidelap-fastener brace force depending on $s, k$, or $w ; C_{r}=$ reduction coefficient that depends on provided $\left(G_{\text {prov }}^{\prime}\right)$ and required shear stiffnesses $\left(G_{\text {req } / \mathrm{d}}^{\prime}\right)=0.75+(1 / 4) \times\left(G_{\text {req/d }}^{\prime} / G_{\text {prov }}^{\prime}\right)^{2}$ (Helwig and Yura $2008 \mathrm{~b}) ; s, k$, and $w=$ respective factors that depend on number of sidelap fasteners, number of end fasteners, and deck width; and other parameters have been defined previously. Respective recommended values of $s, k$, and $w$ are presented in Tables 1-3. Eq. (5) was developed for a twin-beam system, in which there is sheeting on only one side of the beams; therefore the diaphragm braces two beams. For a system with multiple beams, brace forces are likely to be reduced significantly, due to sheeting on both sides of the beams. Egilmez et al. (2016) recommended using the following expression to quantify the reduction in brace forces due to multiple beams (where $n=$ number of beams) braced by deck sheeting:

$$
N_{g}=\frac{0.5 n}{(n-1)}
$$

For exterior beams, in which sheeting is on one side, the reduction factor $N_{g}$ should not be used. However, for exterior beams with little or no overhangs, the loading can be substantially smaller. Depending on whether the LRFD or allowable strength design (ASD) format is used in design, proper load factors should be applied to the strength of the end-fastener and sidelap-fastener connections. Luttrell (1981) recommended using a resistance factor, $\phi$, of 0.65 for LRFD and a factor of safety, $\Omega$, of 2.5 for ASD. A design example is provided in the Appendix. The strength of a diaphragm can also be governed by local or global buckling of the diaphragm. These failure modes should also be checked in design.

\section{Conclusions}

A computational study was conducted to present solutions for the strength requirements of shear diaphragms utilized for stability bracing of simply supported steel beams during construction. A FEA model was utilized to determine the stability-induced brace forces that develop at end-fastener and sidelap-fastener connections. Equations were recommended for both stocky and slender beams to estimate the brace forces as a function of number of end and sidelap fasteners, as well as the width of the diaphragm. The equations were based upon the stiffness requirement of providing four times the ideal stiffness to control deformations, a construction stress level of $210 \mathrm{MPa}$ (30 ksi), and the initial imperfection magnitude of $\theta_{o}=(L / 500 d)$. In building applications, design provisions permit smaller initial imperfections to be adopted in design (AISC 2010). In such cases, the expression in Eq. (5) can be reduced proportionally.

This study enables previous work on strength requirements of shear diaphragms to be applied to slender beams and introduces

\begin{tabular}{|c|c|c|c|c|}
\hline \multirow[b]{2}{*}{ Deck width } & \multicolumn{2}{|c|}{$w_{e}$ for end-fastener connections } & \multicolumn{2}{|c|}{$w_{s}$ for sidelap-fastener connections } \\
\hline & $h / t_{w} \leq 60$ & $60<h / t_{w} \leq 160$ & $h / t_{w} \leq 60$ & $60<h / t_{w} \leq 160$ \\
\hline $610 \mathrm{~mm}$ with four end fasteners & 1.0 & 1.0 & 1.0 & 1.0 \\
\hline $914 \mathrm{~mm}$ with four end fasteners & 1.0 & 1.2 & 1.0 & 1.0 \\
\hline $914 \mathrm{~mm}$ with seven end fasteners & 1.0 & 1.0 & 1.0 & 1.0 \\
\hline
\end{tabular}

Table 3. Values for $w$ That Reflect the Effects of Deck Width on Brace Forces 
expressions for sidelap fastener brace forces, resulting in a comprehensive design procedure for diaphragms that brace simply supported beams. Design engineers can refer to stiffness requirements from the literature to identify a deck form system that has sufficient stiffness to brace a beam during construction. The strength requirement [Eq. (5)] can then be used to check whether the respective forces that develop at the end and sidelap fasteners exceed the capacity of the deck-to-girder fastener connections at deck ends and deck-to-deck fastener connections at sidelaps by utilizing the expressions provided by Luttrell (1981).

In bridge applications, relying on shear diaphragms as a bracing source in the positive moment region can lead to a decrease in the required number of intermediate cross frames or diaphragms during construction. The past AASHTO specifications limited the maximum spacing between cross frames and diaphragms to $7.6 \mathrm{~m}(25 \mathrm{ft})$. The spacing limit was removed from the AASHTO (1994) LRFD specification, primarily due to frequently reported fatigue problems around the brace locations. However, many design engineers still rely on 7.6-m (25-ft) spacing between cross frames (Egilmez et al. 2016). Design engineers can use the design procedure explained earlier to determine whether the diaphragm bracing system can be relied upon to allow an increase in spacing from the commonly employed

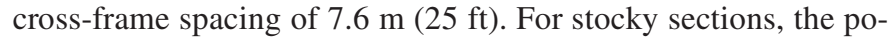
tential of deck form systems to brace bridge girders for a clear span of $15.2 \mathrm{~m}(50 \mathrm{ft})$ have been verified by laboratory tests, as well as field applications (Egilmez et al. 2012, 2016). A detailed experimental program would clearly be requisite for utilizing the recommended brace strength requirements in the design of deck form systems to brace 15.2-m (50-ft)-long slender I-girders.

\section{Appendix. Design Example}

\section{Flooring System}

The flooring system consists of a series of eight simply supported $W 460 \times 68$ (U.S. $W 18 \times 46)$ beams $[d=459 \mathrm{~mm}(18.1$ in. $)]$ spanning $12 \mathrm{~m}(39 \mathrm{ft})$. The tributary width of deck bracing a single beam $\left(s_{d}\right)=2.4 \mathrm{~m}(7.9 \mathrm{ft})$. There is no intermediate discrete bracing system. Determine the required thickness of the deck sheet to provide stability bracing to interior beams during concrete cast:

$M_{u}=260 \mathrm{kN} \cdot \mathrm{m}(2,300 \mathrm{kip} \cdot \mathrm{in}).\left[\phi M_{r}=320 \mathrm{kN} \cdot \mathrm{m}(2,832 \mathrm{kip} \cdot\right.$ in.)] is the upper limit of elastic behavior (Ziemian 2010); and construction stress level is $202 \mathrm{MPa}(29.3 \mathrm{ksi})$.

\section{Check Lateral Torsional Buckling of Beam with $L b=12 m$ (39 ft)}

Assume the entire load is applied at the top flange. Due to top flange loading, moment gradient factor, $C_{b}$, should be modified as follows: $C_{b}^{*}=C_{b} / 1.4$ (Ziemian 2010). Therefore, $C_{b}^{*}=$ $C_{b} / 1.4=1.14 / 1.4=0.81$. The capacity of the beam can be obtained by the following expression (Ziemian 2010):

$$
\begin{aligned}
\phi M_{n} & =\phi C_{b}^{*} M_{g}=\phi C_{b}^{*} \frac{\pi}{L_{b}} \sqrt{E I_{y} G J+\frac{\pi^{2} E^{2} C_{w} I_{y}}{L_{b}^{2}}} \\
& =55.9 \mathrm{kN} \cdot \mathrm{m}(495 \mathrm{kip} \cdot \text { in. })
\end{aligned}
$$

\section{Brace Stiffness Requirement}

$$
\begin{aligned}
G_{\text {req } / \mathrm{d}}^{\prime} & =4 G_{i}^{\prime}=4 \frac{\left(M_{u}-\varphi C_{b}^{*} M_{g}\right)}{s_{d} m d} \\
& =4 \frac{(260.0-55.9)}{2.4 \times 0.5 \times 0.459}=1482.4 \mathrm{kN} / \mathrm{m} / \mathrm{rad}(8.5 \mathrm{kip} / \mathrm{in} . / \mathrm{rad})
\end{aligned}
$$

A diaphragm with $G_{\text {req } / \mathrm{d}}^{\prime}=1,483 \mathrm{kN} / \mathrm{m} / \mathrm{rad}$ (8.5 kip/in. $\left./ \mathrm{rad}\right)$ should be provided. Expressions provided by Luttrell (1981) can be used to select an appropriate diaphragm. For example, a diaphragm with a panel length and width of 2,440 $\mathrm{mm}(8 \mathrm{ft})$, sheet thickness of $0.91 \mathrm{~mm}(20 \mathrm{ga})$, and sheet width of $610 \mathrm{~mm}$ (24 in.) has effective shear stiffness of $2,320 \mathrm{kN} / \mathrm{m} / \mathrm{rad}$ (13.2 kip/in./rad) for a fully fastened deck configuration at the ends (four end fasteners) and five sidelap fasteners

$$
\begin{aligned}
\phi G_{\text {prov }}^{\prime} & =0.65 \times 2,320=1,508 \mathrm{kN} / \mathrm{m}(8.6 \mathrm{kip} / \text { in. })>G_{\text {req } / \mathrm{d}}^{\prime} \\
& =1,483 \mathrm{kN} / \mathrm{m}(8.5 \mathrm{kip} / \text { in. })
\end{aligned}
$$

\section{Brace Strength Requirement}

Use Eq. (5) to obtain reasonable estimates of maximum end and sidelap fastener brace forces. These expressions were developed for a twin-beam system. For a system with multiple beams, these expressions can be modified by the reduction factor $N_{g}=$ $0.5 \times 8 /(8-1)=0.57$. $G_{\text {prov }}^{\prime}$ is slightly higher than $G_{\text {req } / \mathrm{d}}^{\prime}$. Therefore, $C_{r}$ can be taken as 1.0

$$
\begin{aligned}
F_{b r-e}= & N_{g} C_{r} s_{e} k_{e} w_{e} \frac{M_{u} L}{d^{2}}=0.57 \times 1.0 \times 0.0003 \\
& \times 1.0 \times 1.0 \frac{260 \times 12}{0.459^{2}}=2.22 \mathrm{kN}(0.5 \mathrm{kip}) \\
F_{b r-s}= & N_{g} C_{r} s_{s} k_{s} w_{s} \frac{M_{u} L}{d^{2}}=0.57 \times 1.0 \times 0.00025 \times 1.0 \\
& \times 1.0 \frac{260 \times 12}{0.459^{2}}=1.85 \mathrm{kN}(0.4 \mathrm{kip})
\end{aligned}
$$

The shear strength of a deck sheet to structural member fastener connection with mechanical fasteners is given by Luttrell (1981). Use $\phi=0.65, F_{y}=345 \mathrm{MPa}$, and $t=0.91 \mathrm{~mm}(20 \mathrm{ga})$

$$
\begin{aligned}
\phi Q_{f} & =\frac{F_{y} t}{31.5}\left(1-\frac{F_{y}}{1380}\right)=0.65 \frac{345 \times 0.91}{31.5}\left(1-\frac{345}{1380}\right) \\
& =4.86 \mathrm{kN}(1.1 \mathrm{kip})\left(F_{b r-e}\right)=2.2 \mathrm{kN}(0.5 \mathrm{kip})
\end{aligned}
$$

The shear strength of a sheet to sheet fastener connection at sidelaps is given by Luttrell (1981). Use $\phi=0.65, d=$ diameter of the screw $=12 \mathrm{~mm}$, and $t=$ sheet thickness $=0.91 \mathrm{~mm}(20 \mathrm{ga})$

$$
\begin{aligned}
\phi Q_{s} & =0.793 d t=0.65 \times 0.793 \times 12 \times 0.91 \\
& =5.63 \mathrm{kN}(1.3 \mathrm{kip})\left(F_{b r-s}\right)=1.9 \mathrm{kN}(0.4 \mathrm{kip})
\end{aligned}
$$

\section{References}

AASHTO. (1994). LRFD bridge design specifications, 1st Ed., Washington, DC.

AASHTO. (2014). LRFD bridge design specifications, 7th Ed., Washington, DC.

AISC. (2010). Code of standard practice for steel buildings and bridges, 14th Ed., Chicago.

ANSYS 11.0 [Computer software]. ANSYS, Canonsburg, PA.

CANAM Steel Works Inc. (2006). Steel deck diaphragm catalogue, Boucherville, Canada. 
Davies, J. M. (1982). Manual of stressed skin diaphragm design, Wiley, New York.

Egilmez, O., Helwig, T., Herman, R. (2005). "Strength of metal deck forms used for stability bracing of steel bridge girders." Proc., Structural Stability Research Council/North American Steel Construction Conf., Montreal, 257-276.

Egilmez, O., Helwig, T., and Herman, R. (2012). "Buckling behavior of steel bridge I-girders braced by permanent metal deck forms." J. Bridge Eng., 10.1061/(ASCE)BE.1943-5592.0000276, 624-633.

Egilmez, O., Helwig, T., and Herman, R. (2016). "Using metal deck forms for construction bracing of steel bridges.” J. Bridge Eng., 10.1061/ (ASCE)BE.1943-5592.0000864, 04015085.

Egilmez, O., Helwig, T., Jetann, C., and Lowery, R. (2007). "Stiffness and strength of metal bridge deck forms." J. Bridge Eng., 10.1061/(ASCE) 1084-0702(2007)12:4(429), 429-437.

Helwig, T. A., and Frank, K. H. (1999). "Stiffness requirements for diaphragm bracing of beams." J. Struct. Eng., 10.1061/(ASCE) 0733-9445(1999)125:11(1249), 1249-1256.
Helwig, T. A., and Yura, J. A. (2008a). "Shear diaphragm bracing of beams. I: Stiffness requirements.” J. Struct. Eng., 10.1061/(ASCE)0733-9445 (2008)134:3(348), 348-356.

Helwig, T. A., and Yura, J. A. (2008b). "Shear diaphragm bracing of beams. II: Design requirements." J. Struct. Eng., 10.1061/(ASCE)0733-9445 (2008)134:3(357), 357-363.

Luttrell, L. D. (1981). Steel deck institute diaphragm design manual, 1 st Ed., Steel Deck Institute, St. Louis.

TxDOT (Texas Department of Transportation). (2015). "Permanent metal deck forms standard." TxDOT Bridge Division, Austin, TX.

Vardaroglu, M. (2014). "Strength requirements of shear diaphragms used to brace steel I-beams." M.Sc. thesis, Izmir Institute of Technology, Izmir, Turkey.

Wang, L., and Helwig, T. A. (2005). "Critical imperfections for beam bracing systems.” J. Struct. Eng., 10.1061/(ASCE)0733-9445(2005)131:6 (933), 933-940.

Winter, G. (1960). "Lateral bracing of columns and beams." ASCE Trans., $125,809-825$.

Ziemian, R., ed. (2010). Guide to stability design criteria for metal structures, 6th Ed., JWS, New York. 